Article

\title{
The Use of Energy Storage Systems for Supporting the Voltage Needs of Urban and Suburban Railway Contact Lines
}

\section{Diego Iannuzzi ${ }^{1, *}$, Enrico Pagano ${ }^{1}$ and Pietro Tricoli ${ }^{2}$}

1 Electrical Engineering Department, University of Federico II, Naples, via Claudio 21, 80125 Naples, Italy; E-Mail: enpagano@unina.it

2 School of Electronic, Electrical and Computer Engineering, University of Birmingham, Gisbert Kapp Building, Birmingham B15 2TT, UK; E-Mail: p.tricoli@bham.ac.uk

* Author to whom correspondence should be addressed; E-Mail: iandiego@unina.it; Tel.: +39-081-768-3232; Fax: +39-081-768-3223.

Received: 23 November 2012; in revised form: 13 March 2013 / Accepted: 18 March 2013 / Published: 27 March 2013

\begin{abstract}
The paper aims to contribute to the use of electric double layer capacitor (EDLC) sets for boosting voltages of contact lines in urban and suburban railway traction systems. Different electrical configurations of contact lines are considered and investigated. For each of them, proper mathematical models are suggested to evaluate the electrical performances of the contact lines. They give rise, also, to sample design procedures for the sizing of the most appropriate energy storage systems, to be distributed along the lines, for boosting line voltages and avoiding undesired voltage drops. A numerical example based on the "Cumana" suburban Naples railway network is presented to give an idea of the weights and sizes of electric double layer capacitors needed to boost the voltage of a sample contact line. In particular, three different EDLC systems, for a overall installed energy of $9.6 \mathrm{kWh}$, have been placed nearby the stations presenting the highest voltage drops during the most representative situation of trains' service. The new voltage drop is equal to $32 \%$ of that obtained in absence of EDLCs.
\end{abstract}

Keywords: energy management; light railway systems; power peak compensation; EDLC storage systems 


\section{Introduction}

Electrical energy storage systems are composite sets of electrochemical batteries and/or electric double layer capacitors (EDLCs), singly supplied by power electronics devices. New generations of electrochemical batteries (lithium batteries) and EDLCs [1-5], together with the widespread availability of cheap power electronics converters, make it possible to realise systems that are not too expensive and address previously unacceptable disadvantages. They are capable of allowing a controlled bi-directional flow of electrical energy by stepping up or down converter voltages between feeding lines and storage components [6]. A proper design of storage capacities allows one to use electrical storage systems for different practical applications. Researchers are now paying increased attention to different utilisations of these systems in urban and suburban railway traction systems [7-9]. The use of energy storage devices can become very useful in all means of transport, because they can be made capable either of improving efficiency by recovering braking energy and contributing to starting engines or of boosting contact lines voltages. The use has been in the past limited by the weight of electrochemical batteries, by their unsuitable overloading capacities, and by their short lives. Practical applications can be today either stationary or movable [10-13]. In the former case they can be devoted either to recovering energy and returning it or to smoothing electrical power peaks in electrical supply network or to support line voltage. Therefore, they must be installed either near to suburban train stations and streetcar stops (energy recovery) or at some critical points along contact lines. In movable applications they are installed onboard and, hence, they are used to improve efficiency by recovering mechanical energy during braking [14-16]. The action is also useful for smoothing electrical power peaks during train start-up. Until now, the use of storage systems has been not extended to heavy railway traction, because storage systems are insufficient for long distances.

In the following sections of the paper we will pay attention to the boosting action of electrical storage systems, because it seems to us that this practical application can be very useful to solve feeding problems arising today in a lot of big towns. In practice, in the last ten years numerous trolley cars of a new design have gone into service on suburban and city lines. They are generally called jumbo trams, by analogy with the well-known large aircraft. Jumbo trams are longer than traditional streetcars and their traction drives have a higher rated power than any previously used trolley car designs, but one rarely have contact lines been changed or properly updated taking into account the increased current drawn by jumbo trams, as compared with older trolley cars. As a consequence, contact lines sometimes become overloaded, which results in drops in their operating voltages, sometimes below their minimum allowed values. Other trolley cars, travelling in the vicinity in the same or in the opposite direction and fed by the same DC source, can sometimes enter a stand-by condition, due to the protective action of their minimum voltage relays. The same problem arises in suburban traction systems when passenger carrying capacities during daytimes are improved by increasing the number of trains operating simultaneously on the same section of the traction line. To avoid this situation, in many cities, line masters have already resorted to different arrangements for supporting the voltages of contact lines. From a theoretical point of view, all solutions have the goal to limit contact line voltage drops by arranging auxiliary electrical networks that, here and there, boost voltages. Today, the same result can be successfully obtained by the use of EDLC stations allotted along contact line sections [17-22]. This appears to be a good and useful solution to improve line 
performance and avoid undesired voltage drops without substantially changing the structure of the existing contact lines. However, such new configurations are only capable of improving the performances of old contact lines if EDLC sets are properly designed with reference to their size and capacitance, the number and locations of the stations and to strategies used for the involved power electronics devices. The design of EDLC stations can be easily performed by referring to the mathematical models of the whole traction system, involving not only the modified configuration of the contact line, but also the actual operations of streetcars and trains. Sizing procedures used for selecting energy storage systems devoted to boosting contact line voltages are quite different from those to be used for designing EDLC sets devoted to electrical energy recovery. In this case, first of all it must be taken into account that the amount of recovering energy is so higher as nearer EDLCs are to traction drives. For this reason the more proper solution implies the arrangement on board or at the least close to train stations or to streetcar stops. Besides EDLC sizes depend on the amount of recovering energy.

At present, on board and stationary storage devices have been adopted by Bombardier and Siemens. Bombardier has developed a $1 \mathrm{kWh}$ MITRAC Energy saver (300 kW maximum power) used on the roof of LRV in Mannheim public transport in 2005 [12]; an equivalent product, a $1 \mathrm{kWh}$ EnerGstor-Wayside energy storage system - has been prototyped but is not yet operating [23]. Siemens has developed $0.85 \mathrm{kWh}$ SITRAS-MES mobile energy storage system for on-board applications with a maximum power of $288 \mathrm{~kW}$. Moreover, Siemens offers usable $1.7 \mathrm{kWh}$ to $2.5 \mathrm{kWh}$ SITRAS Static Energy Storage (SES) depending on the chosen configuration with a maximum power of $1 \mathrm{MW}$. The system is in full time service in many cities including Bochum, Cologne and Dresden (Germany), Madrid (Spain) and Beijing (China) [24].

Most of the papers in the literature on stationary applications for urban railway networks, discuss mainly their intrinsic capability to save regenerative energy with consequent increase of the energy savings of the systems and reduce voltage drop [7-22]. Among them [17] proposes a stationary solution for voltage regulation at supply line weak points and reduces the peak power input, resulting in lower losses in the supply electrical network lines; [20] discuss sizing of energy storage systems and their optimal charge/discharge control, whereas [21,22] propose optimization procedures for choosing the fundamental characteristics of a energy storage system employed for urban mass transit systems. However, most of the papers do not deal in depth with the main problem of the size evaluation of the stationary energy storage for suburban railway network taking into account the traffic conditions. This aspect appears to be, partially, worked out in [8]. In this paper, we will only deal with EDLC sets having fixed positions and allotted along four standard configurations of contact lines. The mathematical models of each of them are shown, evaluated by referring to generalized function theory [25]. The mathematical models will then be used to carry out design algorithms that enable the selection of a more appropriate set of EDLC stations. The four standard configurations of contact lines are listed below.

- Contact lines supplied by electrical substations at both sides (see Figure 1a).

- Contact lines for going and returning are supplied by DC substations located at both sides of the line. The ends of each line are always considered to have the same voltage value. The maximum voltage drop is reached when a vehicle is right between two substations.

- Contact lines supplied by an electrical substation at one side (see Figure 1b). 
- Contact lines supplied by one electrical substation at intermediate position (see Figure 1c).

The contact lines for going and returning are supplied by a single DC substation located at one end of the track. The voltage drop follows the vehicle displacement and its maximum is reached at the end of the track (the side not supplied by the substation) when a train is there. The contact lines for going and returning are supplied by a single DC substation located in an intermediate position of the track. The voltage drop is the largest when the vehicle is at its farthest point from this intermediate position.

Figure 1. (a) Two side DC supplied contact line; (b) One side DC supplied contact line; (c) Single side DC supplied contact line.

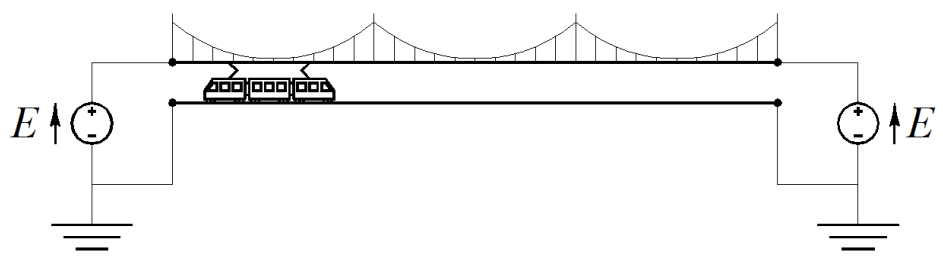

(a)

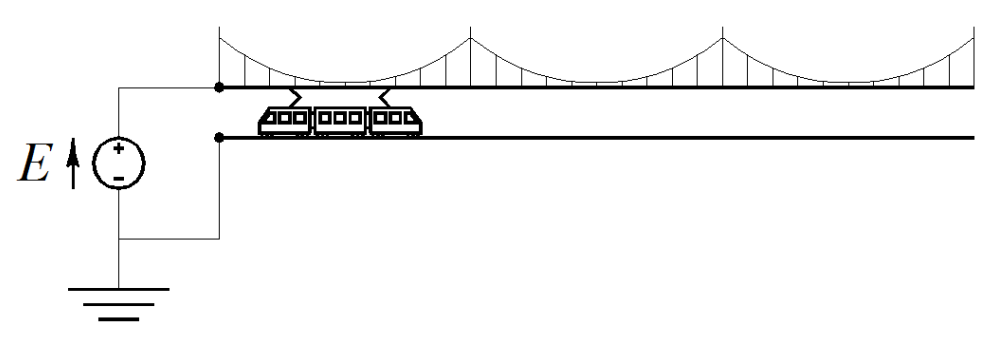

(b)

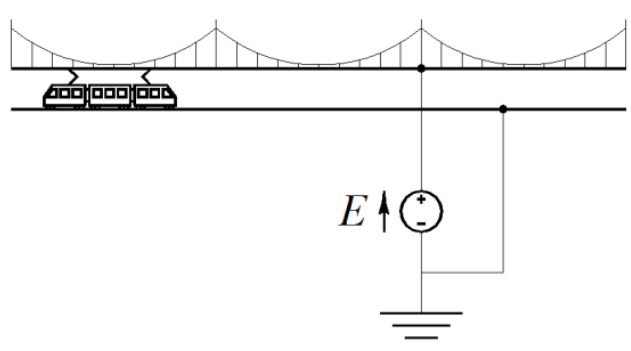

(c)

Mathematical models of all of the contact line configurations, previously taken into account are, generally, carried out on the basis of their equivalent electrical networks and the following sets of input data:

- contact line lengths and cross-section;

- inner characteristics of equivalent DC sources;

- intensities and locations of currents requested by trains;

- $\quad$ selection either of probabilistic or deterministic procedure.

The performance of any contact line configuration can be optimised by using EDLC stations. The main actions of storage devices consists of peak shaving of substation currents and recovering the kinetic energy of translating mass of the vehicles, with consequent reduction of line voltage drops and train currents. The traction system efficiency can be defined as the product of different subsystem efficiencies: substation efficiency, line efficiency and vehicle efficiency. The use of electrical storage devices implies an improvement of each subsystems efficiency and, consequently, also of the traction system efficiency. In both cases, reference has to be made to the current density along the line, expressed in $\mathrm{A} / \mathrm{cm}^{2}$ :

$$
\sigma(x, t)=\frac{J(x, t)}{S(x)}
$$


defined by the ratio between the currents and contact line cross-sections at different times and cross-sectional areas.

After showing the mathematical models of the abovementioned contact line configurations, the paper proposes different algorithms for design guidelines for EDLC support systems for urban and suburban railway contact lines. Previous experience with the use of EDLC devices, in different electrical applications, is integrated with theoretical results to finally attain satisfactory practical results. The validation of the designed composite system could be obtained by a digital simulation by referring to the dynamic operation of the whole system. The envisaged mathematical model of the whole traction system must be utilised by referring to electrical quantities that vary, not only along the lines, but also with time, and by considering a number of linear co-ordinates directly related to the number of means of transportation involved in each contact line section. The use of energy storage systems in the sample case has been extended to electrical energy recovery to compare weights and costs of both their suitable practical use.

\section{Background for the Evaluation of a Sample Mathematical Model}

Each contact line carries the electrical power needed by all of the trains scheduled to operate on that line. The electrical current drawn by each vehicle is dependent on its movement along the line. Therefore this current can be represented by a function of two variables: time and space. Currents are supplied by feeding station(s) and flow from the source to the user. It is easily recognised that in every contact line two different types of currents can be defined as time and location functions: transverse currents, $I[x(t), t]$, flowing to trains and the longitudinal current, $J[x(t), t]$, flowing along the line. The former is a function of the location of an individual train and the power required by it. The latter is a function of the time and the curvilinear abscissa of the line [26], as shown in Figure 2a.

Figure 2. (a) Transverse and longitudinal current distributions along the line (discrete case); (b) Transverse and longitudinal current distributions along the line (continuous case).

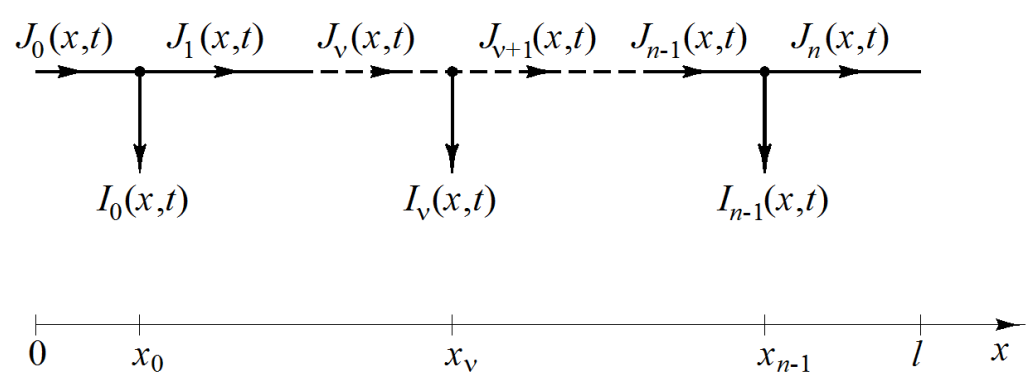

(a)

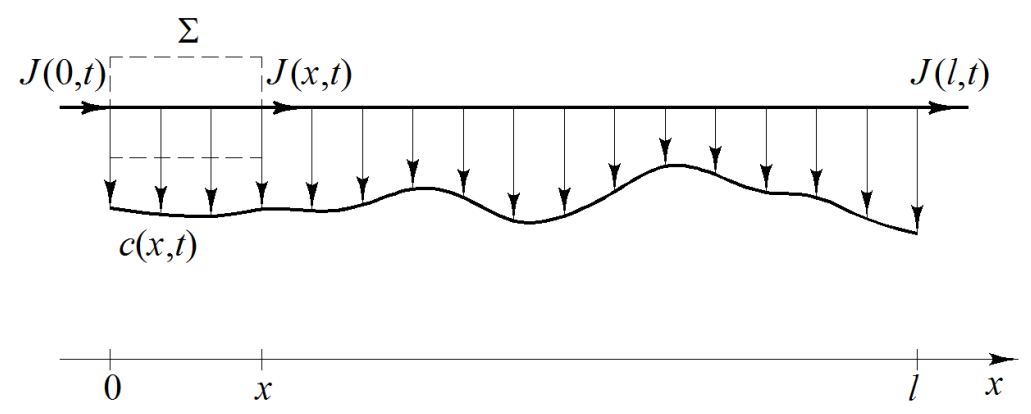

(b) 
Transverse current functions represent the input data of the mathematical model. Longitudinal current functions represent the unknown quantities of the problem. They are needed to define the current densities along the cross-section, $\sigma(x, t)$, of the contact line. In the following, reference is made to a line supplying $\mathrm{n}$ different trains, each one characterised by the progressive subscript $0 \leq v \leq n-1$. Each train is in the point $x_{v}(t)$ and absorbs a current $I_{v}[x(t), t]$. For simplicity, reference is made to the generalized function theory. With this theory, the concentrated currents $I_{v}$ can be represented by a continuous distribution of currents:

$$
c(x, t)=\sum_{v=0}^{n-1} I_{v}(x, t) \delta\left[x-x_{v}(t)\right]
$$

where $\delta(x)$ is the Dirac delta function. Therefore, from the continuity equation of the electric charge, it is finally possible to write (see Figure $2 b$ ):

$$
\int_{\Sigma} \boldsymbol{J} \cdot \boldsymbol{n} d S=0 \Rightarrow J(x, t)=J(0, t)-\int_{0}^{x} c(x, t) d x
$$

where $\boldsymbol{n}$ is the versor normal to the surface $\Sigma$. It is, therefore:

$$
\sigma(x, t)=\frac{J(x, t)}{S(x)}=\frac{1}{S(x)}\left[J(0, t)-\int_{0}^{x} c(x, t) d x\right]
$$

The quantity $\sigma(x, t)$ is very important to develop correct contact line designs and to manage the optimised contact line behaviour. Actually, this quantity leads immediately to the definition of the line voltage drop, i.e.,

$$
\Delta v(x, t)=\int_{0}^{x} \rho \sigma(x, t) d x
$$

where reference is made to the constant cross-section of the contact line. The same function, $\sigma(x, t)$, is useful to evaluate contact line losses [27], i.e.,

$$
P_{c u}=\rho S \int_{0}^{l} \sigma^{2}(x, t) d x
$$

\section{Analytical Solution}

\subsection{Contact Lines Supplied by Electrical Substations at Both Sides}

Using the expression of the current density given by Equation (1), current $J_{0}$ can be determined by putting the global voltage drop along the line equal to zero:

$$
\begin{gathered}
0=\rho \int_{0}^{l} \sigma(x, t) d x=\frac{J_{0}(t) l}{S}-\sum_{\rho=0}^{n}\left[x_{\rho}(t)-x_{\rho-1}(t)\right] \sum_{v=0}^{\rho-1} \frac{I_{v}(t)}{S} \\
J_{0}(t)=\frac{1}{l} \sum_{\rho=0}^{n}\left[x_{\rho}(t)-x_{\rho-1}(t)\right] \sum_{v=0}^{\rho-1} I_{v}(t)
\end{gathered}
$$

After an easy manipulation of summations, we get: 


$$
J_{0}(t)=\frac{1}{l}\left[\sum_{\rho=0}^{n} x_{\rho}(t) \sum_{v=0}^{\rho-1} I_{v}(t)-\sum_{\rho=0}^{n} x_{\rho-1}(t) \sum_{v=0}^{\rho-1} I_{v}(t)\right]=\frac{1}{l} \sum_{v=0}^{n-1}\left[l-x_{v}(t)\right] I_{v}(t)
$$

If $x_{v-1}(t)<x<x_{v}(t)$, the voltage drop is given by:

$$
\Delta v(x, t)=\rho \int_{0}^{x} \sigma(x, t) d x=\rho \frac{J_{0}(t)}{S} x-\rho \sum_{\rho=0}^{v-1}\left[x_{\rho}(t)-x_{\rho-1}(t)\right] \sum_{\mu=0}^{\rho-1} \frac{I_{\mu}(t)}{S}-\rho\left[x-x_{v}(t)\right] \sum_{\mu=0}^{v-1} \frac{I_{\mu}(t)}{S}
$$

\subsection{Contact Lines Supplied by an Electrical Substation at One Side}

In this case, the current in the last branch is always zero and, therefore, the current in the feeder is the sum of the load currents:

$$
J_{0}(t)=\sum_{v=0}^{n-1} I_{v}(t)
$$

If $x_{v}(t)<x<x_{v+1}(t)$, the voltage drop in the generic point of the line is given by:

$$
\Delta v(x, t)=\rho \int_{0}^{x} \sigma(x, t) d x=\frac{\rho}{S}\left[x \sum_{\rho=0}^{v-1} I_{\rho}(t)+\sum_{\rho=v}^{n-1} x_{\rho}(t) I_{\rho}(t)\right]
$$

\subsection{Contact Lines Supplied by One Electrical Substation at Intermediate Position}

The mathematical model of the physical system in Figure 1c, in a case with $n$ trains, each placed at $x_{v}(t)$ and carrying a current $I_{v}(t)$, can be derived immediately after the mathematical model of the contact lines supplied by an electrical substation located at one side. In fact, if the generator is placed at $x=x_{g}$, this line is equivalent to two half-lines, each one supplied at one of the sides only. The first line is $x_{g}$ long and carries the load of $v$ trains, whereas the second is $l-x_{g}$ long and carries the load of $\mu$ trains, with $v+\mu=n$.

\section{Suitable Locations of EDLCs}

The practical use of EDLC storage systems as a support of contact line voltage requires the evaluation of their appropriate locations and sizing. The resolution of these problems should lead to the selection of the more suitable EDLC configurations offering the maximization of system performances with a minimum cost. The correct approach for the evaluation of EDLC locations and sizing requires the definition of suitable targets. If reference is made to the placement of EDLCs, the most suitable position allows the lowest voltage drops for a given value of the energy injected into the line. This optimal position can be easily evaluated using the mathematical model explained in the previous section. For simplicity of the analytical analysis, the contact line is supplied by an electrical substation located at one side of the track and there is only one train along the line. The current injected into the line by the EDLCs is assumed to be a given function of the time, $i_{c}(t)$. This simplification can be adopted, since generally the EDLCs are not directly connected to the contact line, but they are integrated with a DC-DC power converter, as shown in Figure 3. As well-known, these converters can be driven in a current control mode and, therefore, the current injected into the line can be regulated to 
any assigned reference value. As a conclusion, the EDLC system can be modelled as a current source with a limited energy. This energy represents the stored energy into the EDLC modules.

Figure 3. Connection of EDLCs to the contact line.

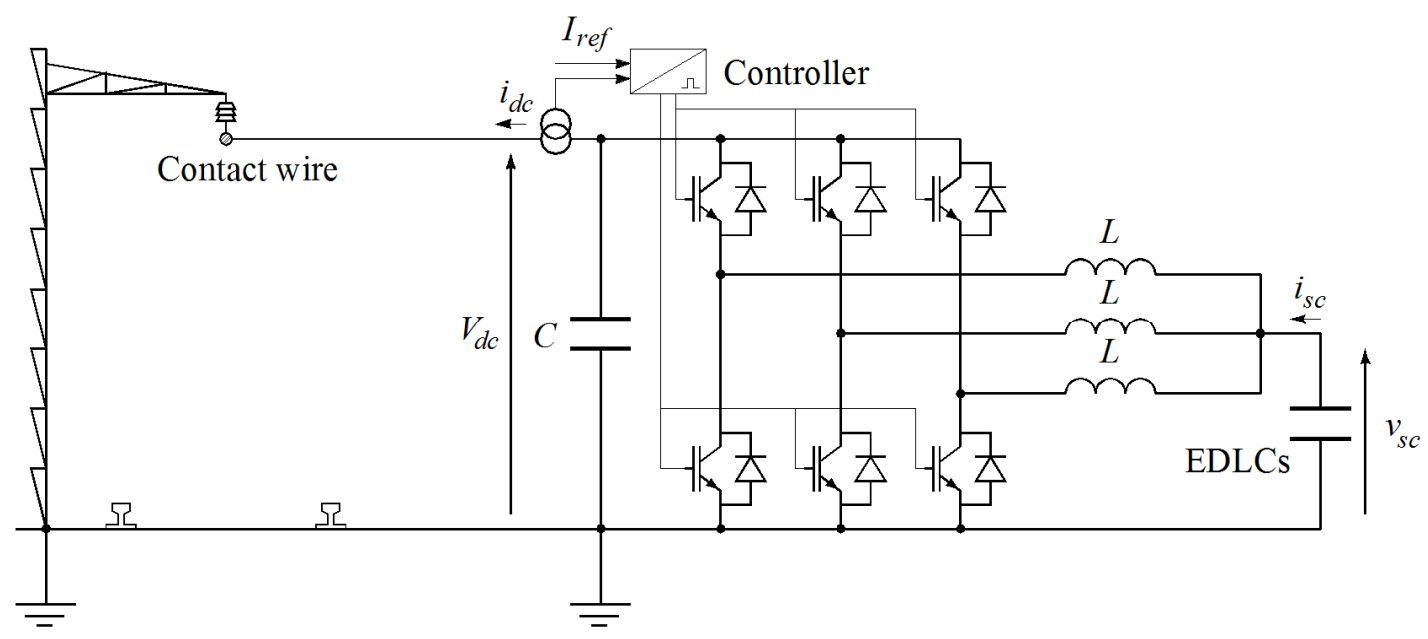

If $x_{t}(t)$ denotes the position of the train at the instant $t, i_{t}(t)$ the current drawn by the train at the instant $t$ and $X_{c}$ is the fixed position of EDLC system, the voltage drop can be easily obtained by the mathematical model previously presented. If $x_{t}(t)<X_{c}$, it is:

$$
\Delta v(x, t)=\left\{\begin{array}{l}
\frac{R}{L} x\left[i_{t}(t)-i_{c}(t)\right], \quad 0<x<x_{t}(t) ; \\
\frac{R}{L} x_{t}(t) i_{t}(t)-\frac{R}{L} x i_{c}(t), \quad x_{t}(t)<x<X_{c} ; \\
\frac{R}{L} x_{t}(t) i_{t}(t)-\frac{R}{L} X_{c} i_{c}(t), \quad X_{c}<x<L,
\end{array}\right.
$$

where $R$ is the total equivalent resistance of the line and $L$ is its length. If otherwise $x_{t}(t)>X_{c}$, it is:

$$
\Delta v(x, t)=\left\{\begin{array}{l}
\frac{R}{L} x\left[i_{t}(t)-i_{c}(t)\right], \quad 0<x<X_{c} ; \\
\frac{R}{L} x i_{t}(t)-\frac{R}{L} X_{c} i_{c}(t), \quad X_{c}<x<x_{t}(t) ; \\
\frac{R}{L} x_{t}(t) i_{t}(t)-\frac{R}{l} X_{c} i_{c}(t), \quad x_{t}(t)<x<L .
\end{array}\right.
$$

Figure $4 \mathrm{a}-\mathrm{c}$ shows a situation where a train is between the feeder and the EDLCs and a situation where it has passed the EDLCs, respectively. Figure $4 \mathrm{~b}$ shows the situation where the train is in the same position of the EDLCs.

Figure 4 shows also that the minimum voltage always occurs at the vehicle's location. In order to minimize the currents and the voltage drops on the line, the best condition is then achieved when the storage system is placed at the train's location. This result is valid whatever the actual position of the train is. Since actually the train does travel along the line, this optimal condition is satisfied in each instant of time only if EDLCs are not fixed and change their position according to that of the train. In other words, the optimal compensation would be achieved if EDLCs were placed onboard of trains. 
Figure 4. (a) Current and voltage drop along the line for different positions of the train; (b) Current and voltage drop along the line for different positions of the train; (c) Current and voltage drop along the line for different positions of the train.

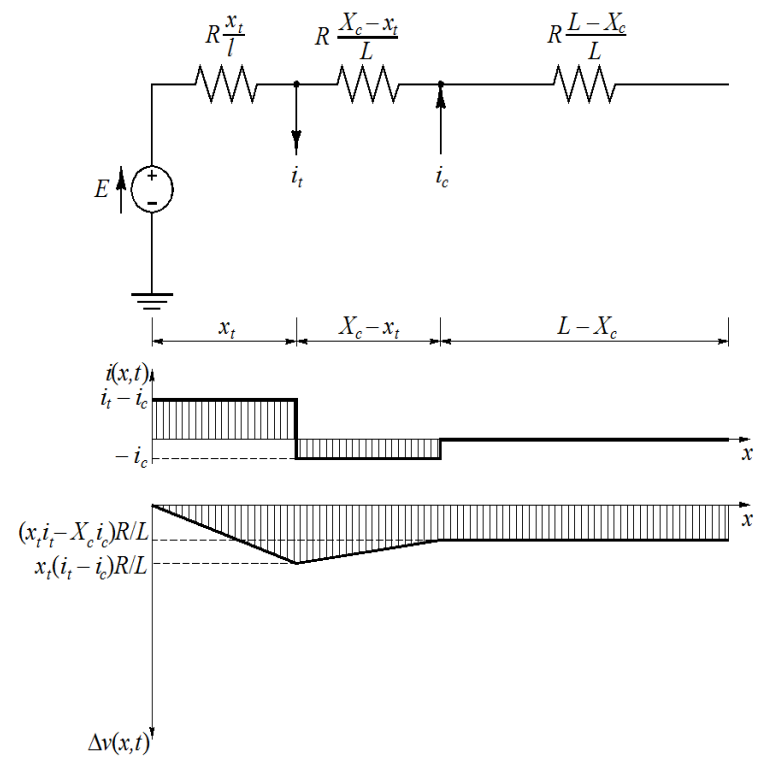

(a)
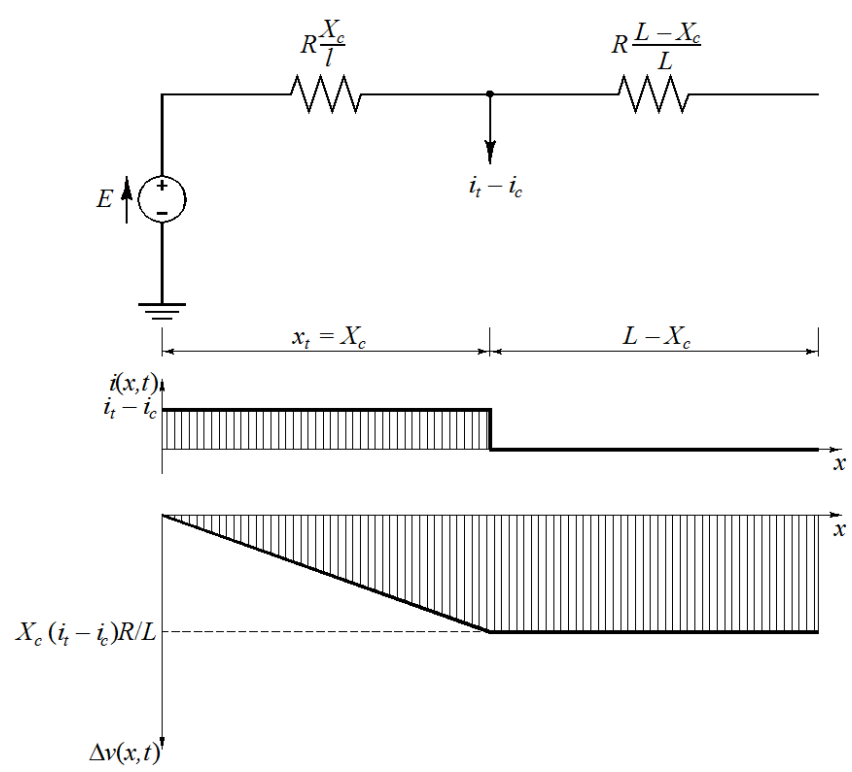

(b)

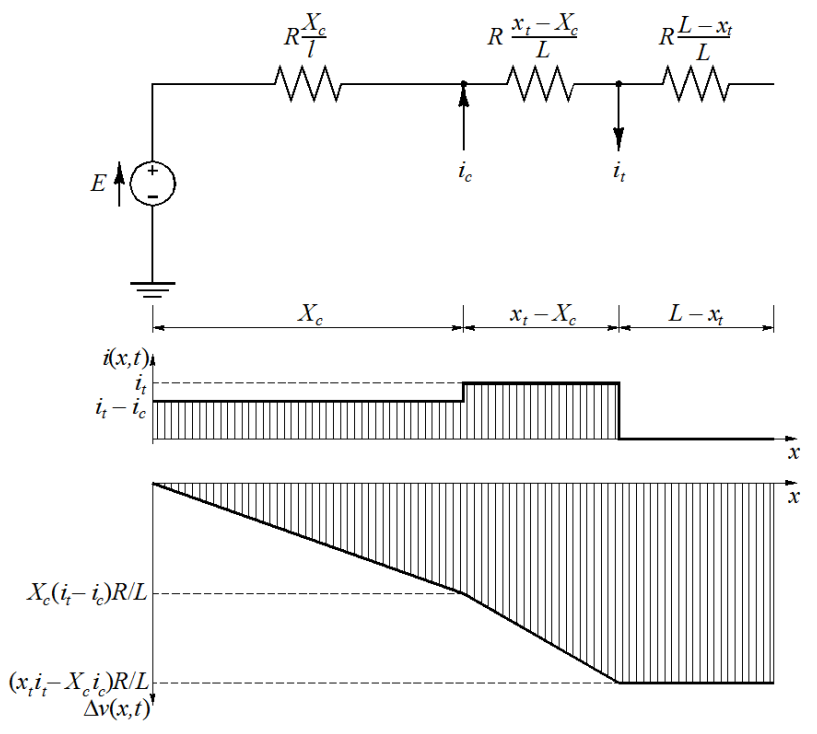

(c)

This situation is out of the scope of this paper, because reference is made to old manufactured vehicles and stationary EDLCs for old contact lines. However, also in this case it is possible to evaluate the more suitable location of EDLCs. For each position of the train, $x_{t}(t)$, it is possible to evaluate from Equations (12) and (13) the voltage drop at train's pantograph, i.e., $\Delta v\left(x_{t}, t\right)$. Supposing that $i_{t}(t)=I_{t}$ and $i_{c}(t)=I_{c}$ are both constant, this voltage drop is also time-independent and is a function of $x_{t}$ only, i.e., $\Delta v\left(x_{t}, t\right)=\Delta V\left(x_{t}\right)$. In these hypotheses, the plot of the train's voltage against the position of the train itself can be represented as Figure 5 shows.

Figure 5 shows that the maximum voltage drop of the train always occurs at the end of the line and is equal to: 


$$
\Delta V(L)=\frac{R}{L}\left(L I_{t}-X_{c} I_{c}\right)
$$

Figure 5. Train's voltage as a function of its position along the line.

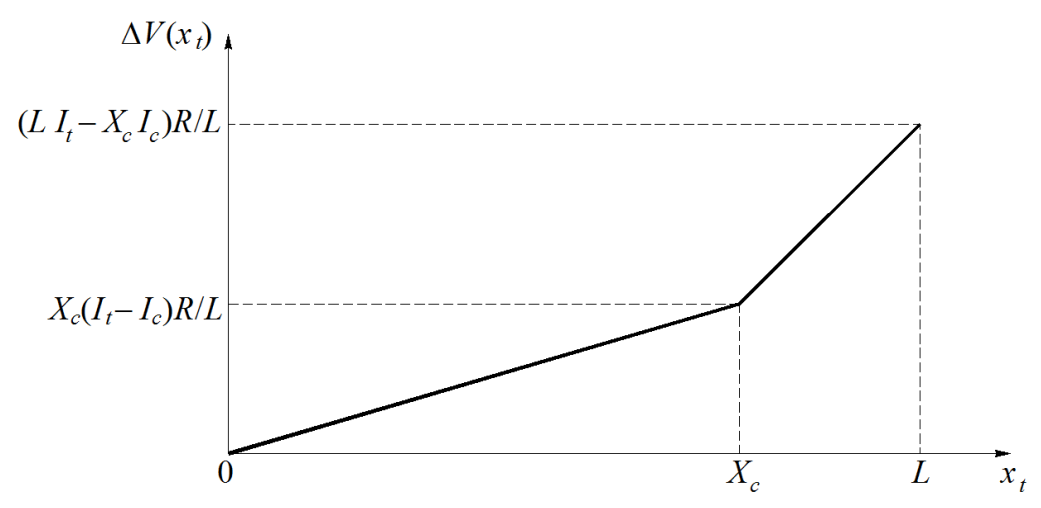

In order to reduce this voltage drop, it is necessary to increase $X_{c}$ as much as possible, compatibly with the topology of the line and its environmental constraints. If there are no physical limitations, EDLCs should be placed at the end of the line, i.e., $X_{c}=L$.

Regarding the choice of $I_{c}$, it is usually convenient to select first a maximum allowable voltage drop for the train, $\Delta V_{\max }$. This value is selected according to the thresholds allowed by the minimum voltage relays. The value $\Delta V_{\max }$ has to be a compromise between size of storage device (cost) and the compensation of line power loss (improvement of line efficiency). From this condition, the EDLC current is zero if the voltage drop caused by the train is less than $\Delta V_{\max }$, i.e.,

$$
\Delta V\left(x_{t}\right)=\frac{R}{L} x_{t} I_{t}<\Delta V_{\max } \Rightarrow I_{c}=0
$$

This condition implies that EDLCs can be unused when the train is within the characteristic distance $X_{t 1}$ :

$$
x_{t}<X_{t 1}=\frac{L}{R} \frac{\Delta V_{\max }}{I_{t}}
$$

When the train passes this point, EDLCs should supply a current that compensates for the voltage drop greater than $\Delta V_{\max }$ caused by the movement of the vehicle beyond $X_{t 1}$. The minimum current, $I_{c}$, preventing the voltage drop from being greater than $\Delta V_{\max }$, is straightforwardly determined as:

$$
I_{c}\left(x_{t}\right)=I_{t}-\frac{L}{R} \frac{\Delta V_{\max }}{x_{t}}
$$

The voltage drop across the EDLCs, $\Delta V_{c}$, is equal to that of the train when $x_{t}<X_{t 1}$, since $I_{c}=0$. Otherwise, it can be easily evaluated from the expression of the current, $I_{c}\left(x_{t}\right)$ :

$$
\Delta V_{c}\left(x_{t}\right)=\Delta V_{t}\left(x_{t}\right)-\frac{L-x_{t}}{L} R I_{c}=\frac{L}{x_{t}} \Delta V_{\max }+\frac{R}{L}\left(x_{t}-L\right) I_{t}
$$

This voltage drop presents a minimum point in the interval $\left[X_{t 1}, L\right]$ for:

$$
X_{t 2}=L \sqrt{\frac{\Delta V_{\max }}{R I_{t}}}
$$


which is greater than $X_{t 1}$, since $\Delta V_{\max }<R I_{t}$, i.e., the maximum allowable voltage is less than the maximum drop caused by a train without EDLCs. The voltage drop of EDLCs as a function of the train's position is represented in Figure 6, where:

$$
\Delta V_{\min }=\sqrt{R I_{t}}\left(2 \sqrt{\Delta V_{\max }}-\sqrt{R I_{t}}\right)
$$

This voltage drop is negative if:

$$
\Delta V_{\max }<\frac{R I_{t}}{4} \Leftrightarrow X_{t 1}<\frac{L}{4}
$$

i.e., the maximum voltage drop of the train is attained when the train is running within one fourth of the line length.

Figure 6. Voltage drop of EDLCs as a function of the time.

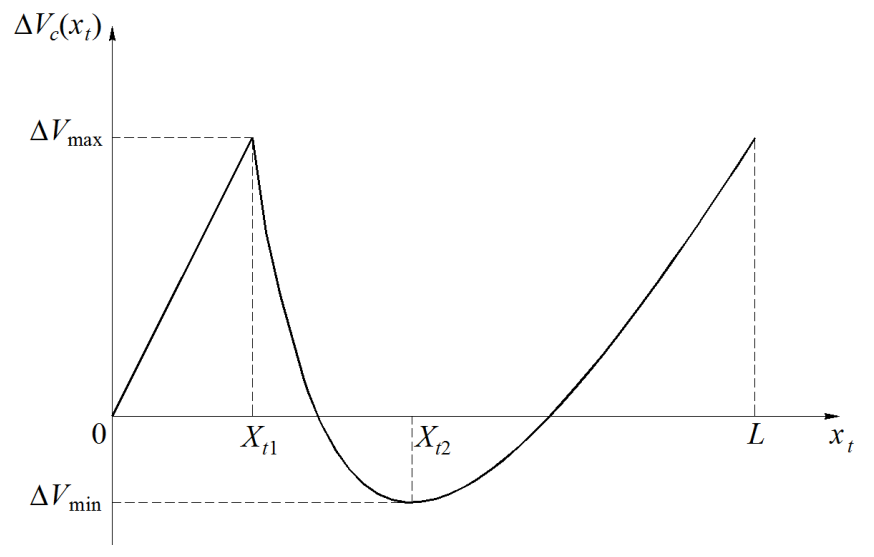

From the knowledge of the EDLC voltage drop, it is easy to evaluate the actual voltage of EDLCs and, also, the power delivered in the interval $\left[X_{t 1}, L\right]$ :

$$
\begin{aligned}
& P_{c}\left(x_{t}\right)=V_{c}\left(x_{t}\right) I_{c}\left(x_{t}\right)=\left[E-\Delta V_{c}\left(x_{t}, t\right)\right] I_{c}\left(x_{t}\right)=\left(E+\Delta V_{\max }\right) I_{t}+ \\
& +R I_{t}^{2}-\frac{L \Delta V_{\max }}{x_{t}}\left(\frac{E}{R}+2 I_{t}\right)+\frac{L^{2}}{R} \frac{\Delta V_{\max }^{2}}{x_{t}^{2}}-\frac{R}{L} I_{t}^{2} x_{t}
\end{aligned}
$$

Previous considerations pointed out that a storage system is capable of effectively limiting the voltage drops caused by trains without changing the capabilities of the line and the onboard arrangements. It is, however, necessary to consider that the current supplied by EDLCs can be assumed to be constant only for a definite time interval dependent on the charge accumulated in the storage system. This problem concerns the sizing of the storage devices, rather than the location, and is treated in the following section.

\section{Designing Guidelines of the EDLC Stacks}

When EDLCs are used to improve the performance of traction systems, they must be properly designed to obtain the expected results. The design procedures are devoted to evaluating the number of EDLC modules, their capacitances and the most useful locations. The input data are the characteristics of the electrical substations, the overhead contact line and the trains. The practical application of any design procedure is complicated by the movement of trains, which can only be taken into account statistically, because the distances and intensities of the currents carried-on by trains vary in a 
stochastic manner, together with their distances from the supplying DC sources. A sample procedure is suggested in the following. It is based on the preliminary consideration that from a theoretical point of view, the best results would be obtained if the number of EDLC sets was chosen equal to the number of trains and located as near to them as possible. In practice, this solution could only be obtained if EDLC sets could be located onboard every vehicle. This solution implies that trains must be designed and manufactured to host onboard EDLC sets. This situation is out of the scope of this paper, because we are dealing with traditional vehicles, moving along a traditional line, fed by old contact lines. By discarding this theory, design procedure must make reference to stationary EDLC sets. The suggested procedure is outlined as follows:

1. The trains are placed on the track in fixed positions. The number of the trains and their positions are given by a preliminary probabilistic study on real traffic conditions on the line. These quantities can be obtained for example as the expected values of random variables describing their stochastic behaviour;

2. The diagram of voltage drop is interpolated by a polynomial approximation in each branch of the line between two electrical substations. This is equivalent to substitute the currents concentrated in trains' locations with continuous current distributions. The chosen approximation has to be made using the mean least square method. The simplest analytical approximation is of second order; it means that the voltage drop function are approximated by parabolas;

3. The maximum allowable voltage drop $\Delta V_{\text {des }}$ is set;

4. The EDLCs are located in the stations which are as close as possible to the points where parabolas have their minimum;

5. For each EDLC is selected the value of energy stored;

6. The parabolas evaluated in step 2 are modified by the introduction of EDLCs sized in Step 5;

7. The size of EDLCs is increased until the voltage drop is lower than $\Delta V_{d e s}$ in any point of the line.

\section{Numerical Example}

A sample suburban railway line is supplied with DC by three electrical substations (ESS) at a rated voltage of $3 \mathrm{kV}$, as shown in Figure 7. Two substations, located in Agnano and Pianura, have power capacities of $7500 \mathrm{~kW}$, whereas the substation located in Torregaveta has a power capacity of $2500 \mathrm{~kW}$. The contact line has a cross-sectional area equal to either $440 \mathrm{~mm}^{2}$ or $380 \mathrm{~mm}^{2}$. The railway track is made of two steel flat-bottomed rails (UNI 50), weighing $50 \mathrm{~kg} / \mathrm{m}$. The resistance of the contact lines and the rails are reported in Tables 1-3 for the three lines connecting the substations.

The trains travelling on the track are the ET400 power cars. Each car is equipped with four MCTC52072C DC motors, having a rated power of $275 \mathrm{~kW}$ and hourly power of $300 \mathrm{~kW}$. The electric motors are controlled by a DC/DC converter with six GTOs.

Each train includes two identical units, each one made up of one powered vehicle, having a full load translating mass $m_{t}=114,800 \mathrm{~kg}$. The maximum train speed is $85 \mathrm{~km} / \mathrm{h}$. The train acceleration and deceleration rates are respectively $a=1 \mathrm{~m} / \mathrm{s}^{2}$ and $d=1 \mathrm{~m} / \mathrm{s}^{2}$. The mean efficiencies of the mechanical transmission, electric motor, inverter, DC-DC converter and EDLCs are respectively $\eta_{\text {mech }}=0.93$, $\eta_{\text {em }}=0.91, \eta_{\text {inv }}=0.95, \eta_{D C D C}=0.95$ and $\eta_{s c}=0.90$. 
An analysis of the timetable shows that two loading conditions are of major interest, i.e., the situations at 8:14 AM and 1:12 PM. At 8:14 AM, 10 trains run on the track: three of them are on the Agnano-Torregaveta line, five are on the Agnano-Pianura line and two are on the Pianura-Torregaveta line. Eight of them are starting after a stop and two are coasting along the Agnano-Torregaveta line. At 1:12 PM, there are 9 trains running: two are starting and one is coasting between Agnano and Torregaveta and between Agnano and Pianura, three are starting between Pianura and Torregaveta. The resulting diagrams of the voltage along the line for the two loading configurations are reported in Figure 8.

Figure 7. Configuration of the sample line considered.

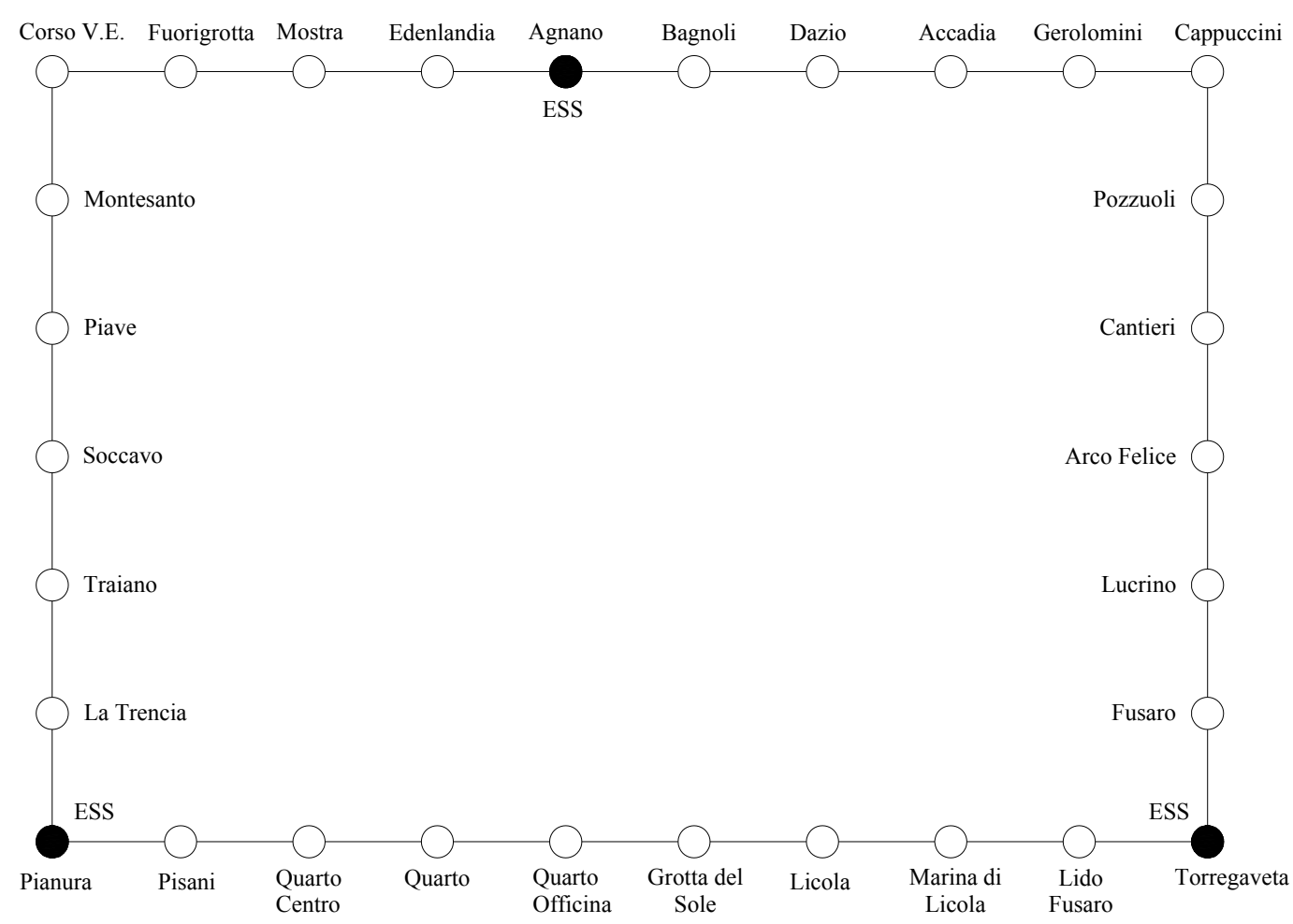

Table 1. Characteristics of the Agnano-Torregaveta branch.

\begin{tabular}{ccccc}
\hline & $\begin{array}{c}\text { Track length } \\
(\mathbf{m})\end{array}$ & $\begin{array}{c}\text { Cross-section area } \\
\left(\mathbf{m m}^{\mathbf{2}}\right)\end{array}$ & $\begin{array}{c}\text { Contact line resistance } \\
(\boldsymbol{\Omega})\end{array}$ & $\begin{array}{c}\text { Rail resistance } \\
(\boldsymbol{\Omega})\end{array}$ \\
\hline Agnano-Bagnoli & 901 & 380 & 0.025 & 0.004 \\
Bagnoli-Dazio & 637 & 380 & 0.018 & 0.003 \\
Dazio-Accadia & 1005 & 440 & 0.020 & 0.004 \\
Accadia-Gerolomini & 1264 & 440 & 0.026 & 0.005 \\
Gerolomini-Cappuccini & 826 & 440 & 0.017 & 0.003 \\
Cappuccini-Pozzuoli & 564 & 380 & 0.016 & 0.002 \\
Pozzuoli-Cantieri & 1224 & 380 & 0.034 & 0.005 \\
Cantieri-Arco Felice & 945 & 440 & 0.019 & 0.004 \\
Arco Felice-Lucrino & 1600 & 440 & 0.033 & 0.006 \\
Lucrino-Fusaro & 2451 & 440 & 0.050 & 0.010 \\
Fusaro-Torregaveta & 1606 & 440 & 0.033 & 0.006 \\
\hline
\end{tabular}


Table 2. Characteristics of the Agnano-Pianura branch.

\begin{tabular}{ccccc}
\hline & $\begin{array}{c}\text { Track length } \\
(\mathbf{m})\end{array}$ & $\begin{array}{c}\text { Cross-section area } \\
\left(\mathbf{m m}^{\mathbf{2}}\right)\end{array}$ & $\begin{array}{c}\text { Contact line resistance } \\
(\boldsymbol{\Omega})\end{array}$ & $\begin{array}{c}\text { Rail resistance } \\
(\boldsymbol{\Omega})\end{array}$ \\
\hline Agnano-Edenlandia & 657 & 440 & 0.013 & 0.003 \\
Edenlandia-Mostra & 966 & 440 & 0.020 & 0.004 \\
Mostra-Fuorigrotta & 843 & 440 & 0.017 & 0.003 \\
Fuorigrotta-Corso V. E. & 1900 & 440 & 0.039 & 0.007 \\
Corso V. E.-Montesanto & 2421 & 440 & 0.049 & 0.010 \\
Montesanto-Piave & 3387 & 380 & 0.138 & 0.027 \\
Piave-Soccavo & 495 & 380 & 0.020 & 0.004 \\
Soccavo-Traiano & 652 & 380 & 0.027 & 0.005 \\
Traiano-La Trencia & 1976 & 380 & 0.080 & 0.016 \\
La Trencia-Pianura & 952 & 380 & 0.039 & 0.007 \\
\hline
\end{tabular}

Table 3. Characteristics of the Pianura-Torregaveta branch.

\begin{tabular}{ccccc}
\hline & $\begin{array}{c}\text { Track length } \\
(\mathbf{m})\end{array}$ & $\begin{array}{c}\text { Cross-section area } \\
\left(\mathbf{m m}^{\mathbf{2}}\right)\end{array}$ & $\begin{array}{c}\text { Contact line resistance } \\
(\mathbf{\Omega})\end{array}$ & $\begin{array}{c}\text { Rail resistance } \\
(\mathbf{\Omega})\end{array}$ \\
\hline Pianura-Pisani & 2836 & 380 & 0.154 & 0.022 \\
Pisani-Quarto Centro & 1836 & 380 & 0.100 & 0.014 \\
Quarto Centro-Quarto & 779 & 440 & 0.032 & 0.006 \\
Quarto-Quarto O. & 901 & 440 & 0.037 & 0.007 \\
Quarto O.-Grotta del Sole & 2659 & 440 & 0.108 & 0.021 \\
Grotta del Sole-Licola & 3118 & 440 & 0.127 & 0.025 \\
Licola-M. di Licola & 1536 & 380 & 0.083 & 0.012 \\
M. di Licola-Lido Fusaro & 3823 & 440 & 0.156 & 0.030 \\
Lido Fusaro-Torregaveta & 2093 & 440 & 0.085 & 0.016 \\
\hline
\end{tabular}

Figure 8. Contact line voltage for the two situations considered.

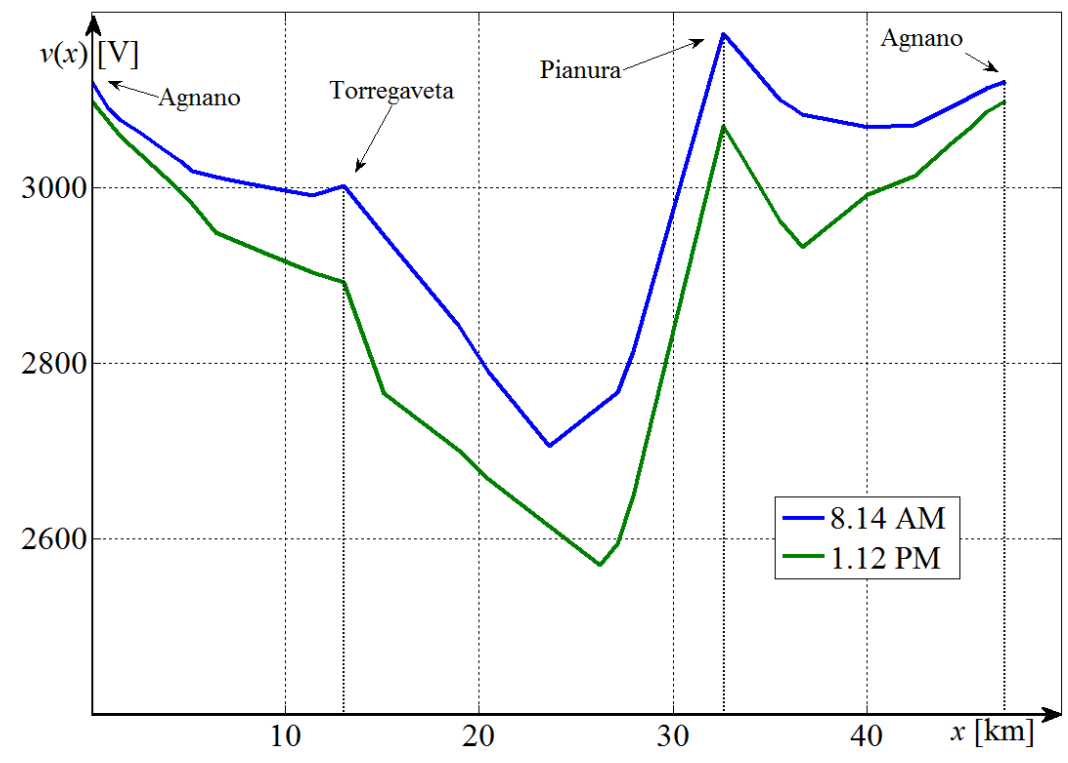

The minimum voltages are $2706 \mathrm{~V}$ at $8: 14 \mathrm{AM}$ and $2570 \mathrm{~V}$ at 1:12 PM. It is desirable to size the EDLC module to ensure that the voltage drop on the line is less than $300 \mathrm{~V}$ under all conditions. 
Therefore, the parabola approximating the best value in the voltage diagram of Figure 7 has to be evaluated with the least squares method.

The relative minima of the three parabolas are $2893 \mathrm{~V}$ between Agnano and Torregaveta, $2578 \mathrm{~V}$ between Torregaveta and Pianura and $2959 \mathrm{~V}$ between Pianura and Agnano. The EDLCs have to be placed in the stations as close as possible to these relative minima, thus, in the stations of Torregaveta, Grotta del Sole and Piave. The requirement for the voltage drop can be satisfied with currents supplied by EDLCs respectively equal to $100 \mathrm{~A}, 300 \mathrm{~A}$ and $150 \mathrm{~A}$. With these currents, the new line voltage diagram is that shown in Figure 9, confirming that the drop is not greater than $300 \mathrm{~V}$ at any point along the line.

Figure 9. Comparison between voltage drops without and with EDLCs at 1.12 PM.

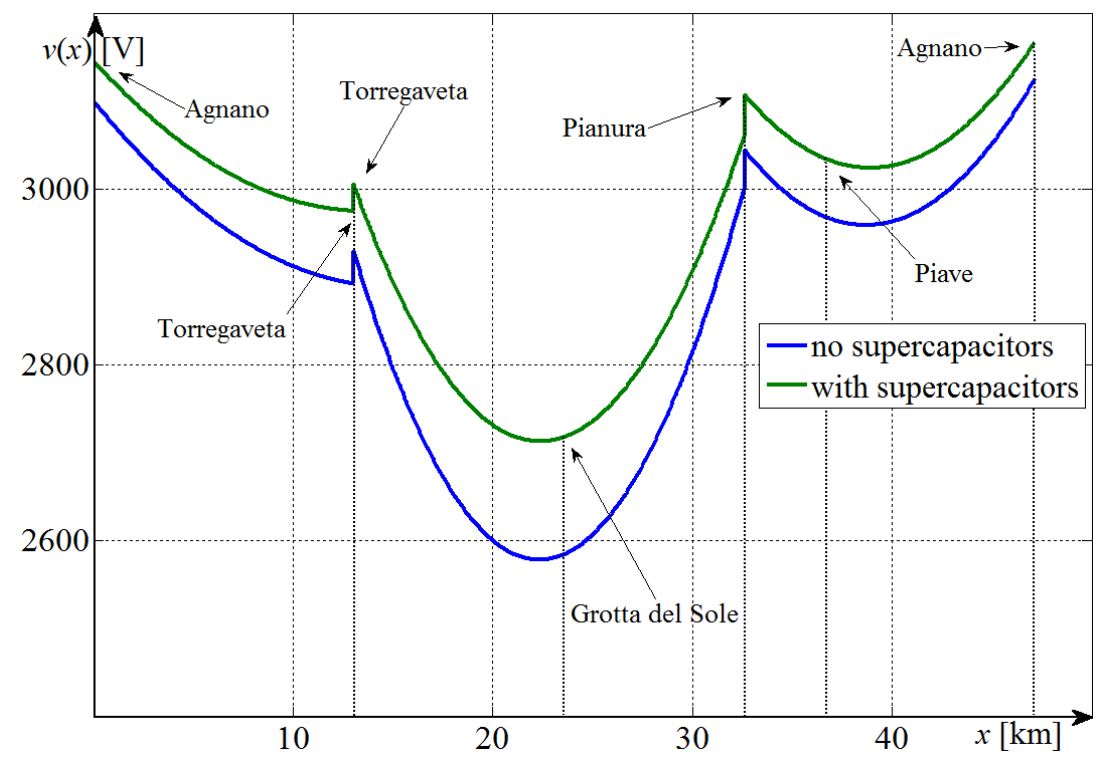

The last step is the determination of the EDLC modules. Considering that the mean starting time of the trains is $T_{s}=20 \mathrm{~s}$, the total energy supplied by each EDLC is that given by Table 4 . EDLCs are connected to the contact line by means of a bidirectional DC-DC converter. In order to increase the voltage ratio between the input and output, a double stage converter can be used, as explained in [28]. In this case, a maximum voltage ratio of 16 can be considered. This means that the minimum voltage of the EDLCs should be at least $189 \mathrm{~V}$, which is about $1 / 16$ of the voltage at the station at Piave. Using the modules of Table 5, it is necessary to connect at least four modules in series, obtaining a string with a rated voltage of $500 \mathrm{~V}$ and a capacitance of $15.75 \mathrm{~F}$.

Table 4. Powers and energy supplied by EDLCs in the stations.

\begin{tabular}{ccccc}
\hline & Voltage (V) & Current (A) & Power (kW) & Energy (kWh) \\
\hline Torregaveta & 2975 & 100 & 297.5 & 1.65 \\
Grotta del Sole & 2713 & 300 & 813.9 & 4.52 \\
Piave & 3024 & 150 & 453.6 & 2.52 \\
\hline
\end{tabular}


Table 5. Main characteristics of EDLC modules.

\begin{tabular}{cc}
\hline Characteristic (Unit) & Value \\
\hline Capacitance $(\mathrm{F})$ & 63 \\
Rated voltage (V) & 125 \\
Minimum voltage (V) & 62.5 \\
Maximum current (5 s) (A) & 750 \\
RMS continuous current (A) & 150 \\
Maximum change of temperature $\Delta \mathrm{T}\left({ }^{\circ} \mathrm{C}\right)$ & 40 \\
Available energy $(\mathrm{Wh})$ & 101.7 \\
\hline
\end{tabular}

On the basis of the data in Table 5, it is necessary to verify if the currents of Table 4 can be supplied by the EDLC modules without damages due to overheating. This is straightforward for the modules placed in Torregaveta and Piave, because the current is not greater than the RMS continuous current of the EDLC modules. For Grotta del Sole, the verification can be carried out by means of a simple thermal model, developed on the basis of the data available. The maximum change of temperature is obtained when the current is equal to the RMS continuous current. Assuming for simplicity a first order thermal model of the module, the change of temperature is:

$$
\Delta T=40\left(1-e^{-\frac{t}{\tau}}\right)
$$

where $\tau$ is the thermal time constant. This time constant can be determined from the maximum current, considering that after five seconds the module reaches the 1st maximum change of temperature. Supposing that the temperature at steady-state will be directly proportional to the square of the ratio of the currents (proportional to losses), the new law for the rate of change of temperature is then:

$$
\begin{aligned}
& \Delta T=\left(\frac{750}{150}\right)^{2} 40\left(1-e^{-\frac{t}{\tau}}\right) \\
& 40=\left(\frac{750}{150}\right)^{2} 40\left(1-e^{-\frac{5}{\tau}}\right) \\
& \tau=122 \mathrm{~s}
\end{aligned}
$$

Using the starting time of the trains $T_{s}=20 \mathrm{~s}$, it is possible to find the change of temperature when the current is $300 \mathrm{~A}$ :

$$
\Delta T=\left(\frac{300}{150}\right)^{2} 40\left(1-e^{-\frac{T_{s}}{\tau}}\right)=24{ }^{\circ} \mathrm{C}
$$

Comparing this value with that reported in Table 5, it is clear that the modules of Grotta del Sole can supply the current requested for the duration of the trains' acceleration. Taking into account that the minimum voltage, $V_{\min }$, is equal to half of the rated voltage, $V_{\text {rated }}$, the required capacitance at each station can be obtained by the expression:

$$
C_{\text {req }}=\frac{2 E_{\text {req }}}{V_{\text {rated }}^{2}-V_{\text {min }}^{2}}=\frac{8 E_{\text {req }}}{3 V_{\text {rated }}^{2}}
$$


Using the values of the required energy given by Table 5, the total number of modules in each station are finally those of Table 6.

Table 6. Number of modules in each station.

\begin{tabular}{ccccccc}
\hline & $\begin{array}{c}\boldsymbol{C}_{\text {req }} \\
\text { (F) }\end{array}$ & $\begin{array}{c}\text { Number } \\
\text { of strings } \\
\text { in series }\end{array}$ & $\begin{array}{c}\text { Number } \\
\text { of strings } \\
\text { in parallel }\end{array}$ & $\begin{array}{c}\text { Total number } \\
\text { of modules }\end{array}$ & $\begin{array}{c}\text { Max voltage } \\
\text { ratio }\end{array}$ & $\begin{array}{c}\text { Max current in } \\
\text { each string(A) }\end{array}$ \\
\hline Torregaveta & 63.36 & 4 & 5 & 20 & 11.9 & 238 \\
Grotta del Sole & 173.57 & 4 & 12 & 48 & 10.9 & 271.3 \\
Piave & 96.77 & 4 & 7 & 28 & 12.1 & 259.2 \\
\hline
\end{tabular}

Previous considerations lead to the conclusion that EDLCs can be used to support voltages in overhead contact lines. Undoubtedly, they can be attractive also for recovering electrical energy during trains' braking. In this case, electrical storage devices should be placed onboard of trains, because energy travels along the shortest path from the traction drive to the storage devices, improving the recovery efficiency. It is easy to show that in such a case, the energy capacity of the storage device is much bigger than that necessary for supporting line voltage. In the hypothesis that the train is travelling at its maximum speed, the electrical energy to be stored in EDLCs for energy recovery would be equal to:

$$
Q_{s c}=\frac{1}{2} m_{t} v_{t}^{2} \eta_{\text {mech }} \eta_{e m} \eta_{i n v} \eta_{d c d c} \eta_{s c}=6.11 \mathrm{kWh}
$$

Using the EDLC modules of Table 5, the energy given by Equation (27) can be stored interconnecting 60 modules, i.e., 30 per car. This set of EDLCs, though smaller than that obtained in the sizing procedure for voltage support (96 modules), has to be multiplied by the number of trains running on the line (nine trains). Therefore when EDLCs are used for energy saving the storage device has to be about five times larger than that needed for voltage support.

\section{Conclusions}

This paper showed how EDLCs can support voltages of urban and suburban contact lines. The evaluation of electrical performances of the lines was made by developing simplified mathematical models suitable for such systems. Models were used for the definition of a sizing criterion for EDLCs with the main objective of reducing voltage drops down to assigned thresholds. The criterion was mainly based on a polynomial approximation of the load distribution, which would be representative of the best fit for different load configurations. The proposed criterion was finally applied to the sample case of a suburban train in South Italy in order to show that the use of EDLCs is feasible from the technical point of view and that the weights and volumes are small enough for the placement of the corresponding storage devices at stations.

\section{Acknowledgements}

The author thanks Francesco Murolo of S.E.P.S.A. who kindly supplied data of the Cumana and Circumflegrea Lines. 


\section{References}

1. Omar, N.; Daowd, M.; van den Bossche, P.; Hegazy, O.; Smekens, J.; Coosemans, T.; van Mierlo, J. Rechargeable energy storage systems for plug-in hybrid electric vehicles-Assessment of electrical characteristics. Energies 2012, 5, 2952-2988.

2. Omar, N.; Daowd, M.; van den Bossche, P.; Hegazy, O.; Coosemans, T.; van Mierlo, J. Electrical double-layer capacitors in hybrid topologies-Assessment and evaluation of their performance. Energies 2012, 5, 4533-4568.

3. Omar, N.; van den Bossche, P.; Verbrugge, B.; van Mierlo, J. Power and life enhancement of battery-electrical double layer capacitor for hybrid electric and charge-depleting plug-in vehicle application. Electrochim. Acta 2010, 55, 7524-7531.

4. Zubieta, L.; Bonert, R. Characterization of Double-Layer Capacitors (DLCs) for Power Electronics Applications. In Proceedings of IEEE Industry Application Conference, St. Louis, MO, USA, 12-15 October 1998; Volume 2, pp. 1149-1154.

5. Conway, B.E. Electrochemical Supercapacitors: Scientific Fundamentals and Technological Applications; Springer: New York, NY, USA, 1999.

6. Hase, S.; Konishi, T.; Okui, A.; Nakamichi, Y.; Nara, H.; Uemura, T. Application of electric double-layer capacitors for energy storage on electric railway. IEEJ. Trans. Ind. Appl. 2004, 123, $517-524$.

7. Turner, A.B. A study of wayside energy storage systems for railway electrification. IEEE Trans. Ind. Appl. 1984, IA-20, 484-492.

8. Barrero, R.; Tackoen, X.; van Mierlo, J. Improving Energy Efficiency in Public Transport: Stationary Supercapacitor Based Energy Storage Systems for a Metro-Network. In Proceedings of IEEE Vehicle Power and Propulsion Conference, Harbin, China, 3-5 September 2008; pp. 1-8.

9. Ciccarelli, F.; Iannuzzi, D. A Novel Energy Management Control of Wayside Li-Ion Capacitors-Based Energy Storage for Urban Mass Transit Systems. In Proceedings of International Symposium on Power Electronics, Electrical Drives, Automation and Motion, Sorrento, Italy, 20-22 June 2012; pp. 773-779.

10. Battistelli, L.; Fantauzzi, M.; Iannuzzi, D.; Lauria, D. Energy Management of Electrified Mass Transit Systems with Energy Storage Devices. In Proceedings of International Symposium on Power Electronics, Electrical Drives, Automation and Motion, Sorrento, Italy, 20-22 June 2012; pp. 1172-1177.

11. Iannuzzi, D.; Tricoli, P. Metro Trains Equipped Onboard with Supercapacitors: A Control Technique for Energy Saving. In Proceedings of International Symposium on Power Electronics, Electrical Drives, Automation and Motion, Pisa, Italy, 14-16 June 2010; pp. 750-756.

12. Steiner, M.; Klohr, M.; Pagiela, S. Energy Storage System with Ultracaps on Board of Railway Vehicles. In Proceedings of European Conference on Power Electronics and Applications, Aalborg, Denmark, 2-5 September 2007; pp. 1-10.

13. Steiner, M.; Scholten, J. Energy Storage on Board of Railway Vehicles. In Proceedings of European Conference on Power Electronics and Applications, Dresden, Germany, 11-14 September 2005.

14. Ciccarelli, F.; Iannuzzi, D.; Tricoli, P. Control of metro-trains equipped with onboard supercapacitors for energy saving and reduction of power peak demand. Transp. Res. C 2012, 24, 36-49. 
15. Iannuzzi, D.; Tricoli, P. Speed-based state of charge tracking control for metro-trains with onboard supercapacitors. IEEE Trans. Power Electron. 2012, 27, 2129-2140.

16. Iannuzzi, D.; Tricoli, P. Optimal Control Strategy of Onboard Supercapacitors Storage System for Light Railway Vehicles. In Proceedings of IEEE International Symposium on Industrial Electronics (ISIE'10), Bari, Italy, 4-7 July 2010; pp. 280-285.

17. Rufer, A.; Hotellier D.; Barrade, P. A Supercapacitor-based energy storage substation for voltage compensation in weak transportation networks. IEEE Trans. Power Deliv. 2004, 19, 629-636.

18. Zhang, Y.; Wu, L.; Hu, X.; Liang, H. Model and Control for Supercapacitor-Based Energy Storage System for Metro Vehicles. In Proceedings of 11th International Conference on Electrical Machines and Systems (ICEMS 2008), Wuhan, China, 17-20 October 2008; pp. 2695-2697.

19. Barrero, R.; Tackoen, X.; van Mierlo, J. Energy savings in public transport. IEEE Veh. Technol. Mag. 2008, 3, 26-36.

20. Iannuzzi, D.; Lauria, D.; Tricoli, P. Optimal design of stationary supercapacitors storage devices for light electrical transportation systems. Optim. Eng. 2012, 13, 689-704.

21. Ciccarelli, F.; Iannuzzi, D.; Lauria, D. Supercapacitors-Based Energy Storage for urban Mass Transit Systems. In Proceedings of 14th European Conference on Power Electronics and Applications (EPE 2011), Birmingham, UK, 30 August-1 September 2011; pp. 1-10.

22. Ciccarelli, F.; Iannuzzi, D.; Lauria, D. Stationary ultracapacitors storage device for improving energy saving and voltage profile of light transportation networks. Transp. Res. C 2012, 21, 321-337.

23. Siemens. Sitras SES: Stationary Energy Storage System for DC Traction Power Supply. Available online: http://w3.siemens.com/smartgrid/global/en/products-systems-solutions/rail-electrification/ dc-traction-power-supply/Documents/SES_PI_131_76.pdf (accessed 20 March 2013).

24. Ticket to Kyoto. Overview of Braking Energy Recovery Technologies in the Public Transport Field. Available online: http://www.tickettokyoto.eu/sites/default/files/download/file/T2K WP2B_deliverable1_20110520.pdf(accessed 20 March 2013).

25. Schwartz, L. Théorie des Distributions à Valeurs Vectorielles (in French); Hermann: Paris, France, 1966; pp. 1-2.

26. McConnell, A.J. Application of Tensor Analysis; Dover Books: New York, NY, USA, 1957.

27. Küpfmüller, K. Einführung in die Theoretische Elektrotechnik (in German); Springer-Verlag: Berlin, Germany, 1968.

28. Ragazzini, G.L.; Lanzetta, F.; Tricoli, P. Dispositivi di Elettronica di Potenza per l'impiego dei Supercondensatori nei sistemi di Trasporto Collettivo Elettrificati (in Italian). In Proceedings of $21^{\circ}$ Seminario Interattivo Azionamenti Elettrici, Bressanone, Italy, 22-23 March 2010.

(C) 2013 by the authors; licensee MDPI, Basel, Switzerland. This article is an open access article distributed under the terms and conditions of the Creative Commons Attribution license (http://creativecommons.org/licenses/by/3.0/). 